\title{
Clinical utility gene card for: Fabry disease
}

\author{
Andreas Gal ${ }^{\star 1}$, Michael Beck ${ }^{2}$ and Bryan Winchester ${ }^{3}$ \\ European Journal of Human Genetics (2012) 20, doi:10.1038/ejhg.2011.178; published online 21 September 2011
}

\section{DISEASE CHARACTERISTICS}

1.1 Name of the disease (synonyms)

Fabry disease.

\subsection{OMIM\# of the disease}

301500.

1.3 Name of the analysed genes or DNA/chromosome segments Alpha-galactosidase A, GLA.

\subsection{OMIM\# of the gene(s)}

300644 .

\subsection{Mutational spectrum}

Disease-causing mutations are mostly point mutations $(\sim 70 \%)$ spread over the seven exons, about $28 \%$ smaller rearrangements affecting $<60$ nucleotides, and about $2 \%$ larger rearrangements affecting $\geq 60$ nucleotides. ${ }^{1}$

1.6 Analytical methods

Bidirectional sequencing of all coding exons and short adjacent intronic sequences.

\subsection{Analytical validation}

Bidirectional sequencing; control of results by parallel use of alternative molecular genetic methods (eg, restriction analysis, ASO-PCR and so on); analysis of samples of family members (as positive and negative controls); comparison with data base entries and data in the literature; quality control through sharing samples.

1.8 Estimated frequency of the disease (incidence at birth ('birth prevalence') or population prevalence) 1 per 30000-35000 births.

1.9 If applicable, prevalence in the ethnic group of investigated person Not applicable.

\subsection{Diagnostic setting}

\begin{tabular}{lll}
\hline & Yes & No \\
A. (Differential) diagnostics & $\bigotimes$ & $\square$ \\
B. Predictive testing & $\bigotimes$ & $\square$ \\
C. Risk assessment in relatives & $\bigotimes$ & $\square$ \\
D. Prenatal & $\bigotimes$ & $\square$ \\
\hline
\end{tabular}

Comment:

A large proportion (figures vary largely from author to author, based on unpublished data of the authors: up to $80 \%$ ) of female carriers manifests disease-specific clinical features, which may be similar in severity to the symptoms of male patients (this is in contrast to the majority of X-linked metabolic diseases), although usually at a later age than male patients. ${ }^{2}$ Nevertheless, in females, a reliable diagnosis can only be made by gene analysis.

\section{TEST CHARACTERISTICS}

\begin{tabular}{|c|c|c|c|c|}
\hline & \multicolumn{2}{|c|}{ Genotype or disease } & \multirow{2}{*}{$\begin{array}{l}\text { A: true positives } \\
\text { B: false positives }\end{array}$} & \multirow{2}{*}{$\begin{array}{l}\text { C: false negative } \\
\text { D: true negative }\end{array}$} \\
\hline & Present & Absent & & \\
\hline \multicolumn{5}{|l|}{ Test } \\
\hline Positive & A & B & $\begin{array}{l}\text { Sensitivity: } \\
\text { Specificity: }\end{array}$ & $\begin{array}{l}A /(A+C) \\
D /(D+B)\end{array}$ \\
\hline Negative & $\mathrm{C}$ & $\mathrm{D}$ & $\begin{array}{l}\text { Positive predictive value: } \\
\text { Negative predictive value: }\end{array}$ & $\begin{array}{l}A /(A+B) \\
D /(C+D)\end{array}$ \\
\hline
\end{tabular}

\subsection{Analytical sensitivity} (proportion of positive tests if the genotype is present) In case of bidirectional sequencing of all coding exons and short adjacent intronic sequences, $\sim 98 \%$ in males and $\sim 96 \%$ in females (unpublished data of the authors).

\subsection{Analytical specificity}

(proportion of negative tests if the genotype is not present) Not appropriate.

\subsection{Clinical sensitivity}

(proportion of positive tests if the disease is present)

The clinical sensitivity can be dependent on variable factors, such as age or family history. In such cases, a general statement should be given, even if a quantification can only be made case by case.

In case of bidirectional sequencing of all coding exons and short adjacent intronic sequences, $\sim 98 \%$ in males and $\sim 96 \%$ in females (unpublished data of the authors).

\subsection{Clinical specificity}

(proportion of negative tests if the disease is not present)

The clinical specificity can be dependent on variable factors such as age or family history. In such cases a general statement

\footnotetext{
${ }^{1}$ Institute of Human Genetics, University Medical Center Hamburg-Eppendorf, Hamburg, Germany; ${ }^{2}$ Center for Child and Adolescent Medicine, University Medical Center Mainz, Mainz, Germany; ${ }^{3}$ Biochemistry Research Group, UCL Institute of Child Health at Great Ormond Street Hospital, University College London, London, UK

*Correspondence: Professor A Gal, Institute of Human Genetics, University Medical Center Hamburg-Eppendorf, Martinistr. 52, Hamburg 20246, Germany. Tel: +49 407410 52120; Fax: +49 407410 55138; E-mail: gal@uke.de
} 
should be given, even if a quantification can only be made case by case.

Practically $100 \%$.

2.5 Positive clinical predictive value (lifetime risk to develop the disease if the test is positive)

In case of known disease-causing mutations, almost $100 \%$ of males and up to $80 \%$ of females develop signs and/or symptoms of the disease (unpublished data of the authors), whereas expressivity is very variable both within the same family and among different families carrying the same mutation.

2.6 Negative clinical predictive value (probability not to develop the disease if the test is negative) Assume an increased risk based on family history for a non-affected person. Allelic and locus heterogeneity may need to be considered.

Index case in that family had been tested:

Practically $100 \%$

Index case in that family had not been tested:

Depending on age and degree of relationship, $\sim 98 \%$ in males and $\sim 96 \%$ in females if bidirectional sequencing of all coding exons and short adjacent intronic sequences was performed (unpublished data of the authors).

\section{CLINICAL UTILITY}

3.1 (Differential) diagnosis: The tested person is clinically affected (To be answered if in 1.10 'A' was marked)

\subsubsection{Can a diagnosis be made other than through a genetic test?}

$\begin{array}{ll}\text { No } & \square \text { (continue with 3.1.4) } \\ \text { Yes } & \text { \ } \\ & \text { Clinically } \\ \text { Imaging } & \\ \text { Endoscopy } & \text { Biochemistry } \\ & \text { Electrophysiology } \\ & \text { Other (please describe) }\end{array}$
have very low alpha-galactosidase $A$ activity and can be diagnosed reliably by an enzymatic test in blood leukocytes. Some male patients with attenuated forms of the disease have considerable residual alpha-galactosidase A activity, although still far below the reference range, and diagnosis must be confirmed by mutation analysis. A pseudodeficiency of alpha-galactosidase $A$ activity (eg, in males carrying the non-disease causing p.D313Y mutation) may also result in low alpha-galactosidase $A$ activity and must be differentiated by molecular genetic testing. The activity of alpha-galactosidase $A$ may be normal in female carriers, therefore a diagnosis of Fabry disease in females can only be made by molecular genetic tests.

Before enzyme replacement therapy is initiated, the diagnosis should be verified in all patients by detection of the disease-causing mutation. ${ }^{3}$

3.1.2 Describe the burden of alternative diagnostic methods to the patient? Small (blood drawing).

3.1.3 How is the cost effectiveness of alternative diagnostic methods to be judged?

Results of an enzyme assay are usually available within 7 days. The biochemical diagnosis costs presently significantly less than a molecular genetic diagnosis.

3.1.4 Will disease management be influenced by the result of a genetic test?

No

Yes $\otimes$

Therapy Depending on the mutation and the clinical

(please describe)

Prognosis

(please describe)

Management

(please describe)

3.2 Predictive Setting: The tested person is clinically unaffected but carries an increased risk based on family history

(To be answered if in 1.10 ' $\mathrm{B}$ ' was marked)

\subsubsection{Will the result of a genetic test influence lifestyle and} prevention?

If the test result is positive (please describe):

Therapeutic options, see 3.1.4; informed family planning if a carrier status has been diagnosed.

If the test result is negative (please describe):

In case of potential heterozygotes, the knowledge of not having an elevated carrier risk results in 'relief' with regard to the familial risk, and allows an informed decision on family planning and prenatal diagnosis.

3.2.2 Which options in view of lifestyle and prevention does a person at-risk have if no genetic test has been done (please describe)?

At present, enzyme replacement therapy (ERT) with $\alpha$-galactosidase $\mathrm{A}$ is the only option to prevent disease progression and serious organ damage. Since life expectancy of untreated patients is significantly reduced both in males and in females, regular monitoring and timely diagnosis of disease-specific signs and symptoms are essential. The major causes of morbidity and mortality are renal failure, cardiovascular disease, and stroke. Therefore, management of patients with Fabry disease requires a multidisciplinary team of medical sub-specialists.

3.3 Genetic risk assessment in family members of a diseased person

(To be answered if in 1.10 'C' was marked)

3.3.1 Does the result of a genetic test resolve the genetic situation in that family?

Yes, $\mathrm{X}$-linked inheritance is proven.

3.3.2 Can a genetic test in the index patient save genetic or other tests in family members?

Yes. Knowing the disease-causing mutation allows specific analysis of the proband's mutation in relatives whose health problems could not be assigned yet to a medical entity. 
3.3.3 Does a positive genetic test result in the index patient enable a predictive test in a family member?

Yes.

\subsection{Prenatal diagnosis}

(To be answered if in 1.10 ' $\mathrm{D}$ ' was marked)

3.4.1 Does a positive genetic test result in the index patient enable a prenatal diagnosis?

Yes.

\section{IF APPLICABLE, FURTHER CONSEQUENCES OF TESTING}

Please assume that the result of a genetic test has no immediate medical consequences. Is there any evidence that a genetic test is nevertheless useful for the patient or his/her relatives? (please describe)

Gene analysis allows diagnosis of carrier state in female relatives of probands.

\section{CONFLICT OF INTEREST}

Authors have received research grants, honoraria for lectures at educational meetings, travel grants, and consultancy fees from Shire HGT and Genzyme.

\section{ACKNOWLEDGEMENTS}

This work was supported by an unrestricted education grant of Shire HGT CECRE (to AG) and by EuroGentest, an EU-FP6 supported NoE, contract number 512148 (EuroGentest Unit 3: 'Clinical genetics, community genetics and public health', Workpackage 3.2).

1 Gal A: Molecular genetics of Fabry disease and genotype-phenotype correlation; in Elstein D, Altarescu G, Beck M (eds): Fabry Disease. Dordrecht, Heidelberg, London, New York: Springer Science + Business Media, 2010, pp 34-50.

2 Germain DP: Fabry disease. Orphanet J Rare Dis 2010; 5: 30.

3 Lidove 0 , West ML, Pintos-Morell G et al: Effects of enzyme replacement therapy in Fabry disease - a comprehensive review of the medical literature. Genet Med 2010; 12: 668-679. 